\title{
Markets and institutional fields: foundational concepts and a research agenda
}

\author{
Nicola Mountford ${ }^{1}\left[\right.$ [D $\cdot$ Susi Geiger ${ }^{2}$
}

Received: 17 June 2020 / Accepted: 26 April 2021 / Published online: 15 May 2021

(c) The Author(s) 2021

\begin{abstract}
We borrow the notion of field from institutional theory to think through how markets and their 'outsides'-or at least one particular manifestation of an 'outside'-stand in a dynamic and interactive relationship. We distinguish the field and the market in terms of issues versus exchange and identity versus position. We argue that the lack of clarity as to how fields and markets differ, relate, overlap, and are bounded, jeopardizes our ability to address important societal debates concerning the roles of markets within and across other areas of social life. It also hinders a consolidation of insights across different approaches to studying markets, even though researchers from different disciplines often address similar concerns. Key questions for which both conceptual and analytical clarity are essential include how markets and their 'outsides' (here: fields) intersect; whether and how diverse sets of actors interact, work, and migrate between fields and markets; and what dynamics may be observable between field and market. We provide four illustrative examples of field/market relationships and a theoretical, methodological, and empirical research agenda for future research into markets and their 'outsides'.
\end{abstract}

Keywords Field $\cdot$ Market $\cdot$ Institutional theory $\cdot$ Market systems $\cdot$ Market studies $\cdot$ Boundaries

As this special issue demonstrates, markets have come to the fore of academic theorizing in marketing (e.g. Giesler \& Fischer, 2017; Humphreys, 2010; Martin \& Schouten, 2014; Mele et al., 2015; Nenonen et al., 2019; Vargo et al., 2017). As per Nøjgaard and Bajde's (2020) recent overview, marketing academics have tended to approach markets from two dominant theoretical perspectives. On the one hand, tracing their lineage back to actor network theory, critical market studies researchers emphasize the active socio-material construction of markets (e.g. Azimont \& Araujo, 2007; Geiger \& Kjellberg, 2021; Kjellberg \& Helgesson, 2006; Onyas \& Ryan, 2015). For market systems dynamics researchers, on the other hand, institutional thinking has served as a useful conceptual foil against which to analyze how markets emerge and change (e.g. Giesler \& Fischer, 2017; Humphreys, 2010; Scaraboto \& Fischer, 2013). Though not explicitly mentioned by Nøjgaard and Bajde (2020), researchers utilizing

Nicola Mountford

Nicola.mountford@mu.ie

Maynooth University School of Business, Maynooth, Ireland

2 College of Business, University College Dublin, Dublin, Ireland the service-dominant logic (SDL) and service ecosystems perspectives have also started to broaden their lens towards markets by including an institutional perspective on value creation (Frow et al., 2016; Hartmann et al., 2018; Vargo \& Lusch, 2016; Vargo et al., 2017). Beyond marketing, organization studies researchers have considered markets as organizational structures, and they too have tended to lean on institutional perspectives (e.g. Ahrne et al., 2015; Anand \& Peterson, 2000; Child \& Rodrigues, 2011; Weber et al., 2008). From a position of near-neglect prior to the year 2000, markets and institutions have thus come to preoccupy different areas of development in marketing theory. While we very much welcome the 'turn to markets' in these different sets of literatures, in this paper we argue that across all of them, the question of what is 'outside' of markets, and how markets interact with their 'outsides', has received rather short shrift (see also Möller et al., 2020).

We borrow the notion of field from institutional theory to think through how markets and their 'outsides'-or at least one particular manifestation of an 'outside'-stand in a dynamic and interactive relationship. We define the field as an agglomeration of diverse sets of actors who take one another into account in a social arena where there is an issue 'at stake', and we define the market as a social arena where 
what is at stake is a position in a system of exchange. By leaning on the institutionalist notion of field, our reflection arguably aligns with conventions within organization studies and market systems dynamics more than with critical market studies or SDL. However, we utilize insights from those latter bodies of research to enrich our discussion of the intersection between market and field with an actor-centric view, in line with recent calls for a stronger focus on actorhood in institutional theory (Patriotta, 2020; Voronov \& Weber, 2020). Additionally, while Möller et al., (2020) have highlighted that there are different 'outsides' to a market (namely focal ecosystem, field, and macro system), we argue that analytically the field is the most pertinent and fertile of these layers. In contrast to the 'focal ecosystem', the field can encompass a wide variety of actors beyond business partners; in contrast to the 'macro system' it is still possible for the analyst to empirically bound it. With its roots in neoinstitutionalism, the notion of field is also theoretically well elaborated.

Indeed, it is difficult to imagine a current institutional conversation that does not include the field in its vocabulary, and many researchers have followed this trend in their exploration of markets. In doing so, however, they have often conflated the two notions of market and field, and this conflation is one of the motivations behind the current paper. Dolbec and Fischer (2015, p. 1449), for instance, define markets as "an organizational field encompassing a set of institutions and actors, governed by institutional logics, supported by institutional work, and characterized by institutional boundaries". Similarly, organization theorists have either merged the two concepts-Zietsma et al. (2017) speak of 'exchange field' and Beckert (2010) of 'market-field'-or used the two terms interchangeably (Rainelli et al., 2016; Sgourev, 2013). We argue that the lack of clarity about how fields and markets relate and differ, whether they overlap or coincide, and what constitutes their boundaries, jeopardizes our ability to address important societal debates concerning the roles of markets within and across other areas of social life. It also hinders a consolidation of insights across different approaches to studying markets, even though researchers from different disciplines often address similar concerns.

We adopt Hoffman's (1999) perspective that fields develop around issues, loosely defined as centers of debate or dialogue that bring various actors together who each have or claim a 'stake' in the issue. Markets, by contrast, revolve around a system of production and consumption that has an exchange at its core (e.g. Geiger et al., 2012). The same actors that gather around an issue in a field may also relate to each other within markets to conduct or influence an exchange, and that market exchange may be influenced by the issue debates within the field (and vice versa). Our position is, therefore, both conceptual and analytical. Conceptually we go beyond Zietsma et al.'s,
(2017) semantic distinction between the 'exchange' and the 'issue' field to argue that a market is something other than a field, but can and often will overlap and share a set of actors with the latter. Moreover, we warn that without this distinction we risk overlooking or misunderstanding the relationship between the market and its outsides. We thus argue that though market and field are dynamically interlinked, they can and should be conceptually distinguished. Analytically, we propose that empirical examination of market and field each starts from a different point. We contend that it is the actors' identification with an issue and/or their positioning in relation to the exchange that determine the (fluid) boundary between the field and the market. Whether or not an actor can be conceptualized as part of a field depends upon their identification with the issue that forms the heart of that field. Whether or not the same actor should be seen as part of a market will depend upon their positioning themselves in relation to the exchanges around which that market revolves. In our research agenda, we think through what this distinction means from a methodological and empirical perspective.

In short, with the current paper we endeavor to bridge the gap between literatures around markets that have developed in different disciplines and subdisciplines, arguing that it is important to have conceptual clarity as well as an analytical gaze and language that facilitates robust conversations across different intellectual traditions. Key questions for which both conceptual and analytical clarity are essential include how markets and their 'outsides' (here: fields) intersect; whether and how actors interact, work, and migrate between fields and markets; and where one can possibly locate boundaries between field and market. While we propose initial answers to these questions, our core goal is to facilitate future conversations by offering some foundational stones for research that span both field and market. To institutional researchers, we suggest that a clear distinction between market and field rather than a conflation of both concepts is of particular value in analyzing what is 'at stake' in these different arenas. In turn, we encourage marketing colleagues to be clearer as to what may lie 'outside' the market and how this 'outside' influences its 'inside'-an issue that has rarely been explicitly addressed in that discipline. To the SDL researcher, we offer a new way of thinking around a core concern-value co-creation in social systems-through our reflection on how what is valued may be determined by the dynamics between the market's insides and its outsides. Finally, we contend that borrowing from the arguably more actor-centric perspective of critical market studies could further enhance our theorization of markets and their 'outsides', contributing in turn to institutionally focused markets research. Our paper thus has conceptual as well as analytical value for researchers of markets across marketing and organization studies. 


\section{Markets and fields - two peas in the same pod?}

Sustainable tourism (Van Wijk et al., 2013), law firms (Sherer \& Lee, 2002), the US chemical industry (Hoffman, 1999), healthcare (Reay \& Hinings, 2005), biotechnology (OwenSmith \& Powell, 2008) and fashion (Dolbec \& Fischer, 2015) have all been described as fields, signaling that a field is not uniquely defined by either economics, industry, or geography. For DiMaggio and Powell (1983 p. 148), fields are identifiable precisely through their identify-ability: "those organizations that, in the aggregate, constitute a recognized area of institutional life." While field theoretical approaches are diverse, ranging from Bourdieusian theory to Fligstein's social action fields (for a recent review see Zietsma et al. 2017), most field conceptualizations include a number of common elements. These are: 1) diverse sets of actors who are in relationship to each other; 2) a common meaning structure; 3 ) institutional infrastructures; 4) hierarchies and status; 5) boundaries to other fields and 6) flux and change (Di Maggio and Powell, 1983; Scott, 1995; Thornton \& Ocasio, 1999; Fligstein, 2001; Scott et al., 2006; Greenwood \& Meyer, 2008; Owen Smith \& Powell, 2008).

Fields emerge when actors begin to form conurbations or aggregations that seek recognition as "areas of institutional life" (DiMaggio \& Powell, 1983, p. 148; Faulconbridge \& Muzio, 2019). DiMaggio and Powell (1983) describe fields as institutionally structured by increased interaction, patterns of interaction, information exchange, and mutual awareness among organizational actors. This structuring creates isomorphic pressures on the field's member organizations. Over time, membership in a field thus becomes the difference between an organization choosing from unlimited possibilities and those that are considered legitimate within a particular group of actors. Where DiMaggio and Powell (ibid.) and Scott et al. (2006) argue that fields typically form around types of focal organizations, Hoffman's (1999) influential conceptualization of the field places issues rather than organizations at the heart of the concept. This makes the field a centre of debate and action where what is legitimate or illegitimate is continuously negotiated and where events trigger new forms of debate that reconfigure fields as new entrants join the debate. It also opens up the field to actors other than organizations. Issues are socially constructed or 'framed', and their reframing can give rise to changes in the field's composition and reach (Furnari, 2018). Seen as issue fields, their existence and raison d'être can be temporary or, in Fligstein and McAdam's (2012) words, 'situational'-once the issue is resolved, the field is likely to dissolve.
To reconcile Hoffman's view with that of more organizationally focused researchers, Zietsma et al. (2017) distinguish between 'issue field' and 'exchange field'. They define the former as identifiable "by the set of actors that interact and take one another into account on particular issues", and the latter as "fields where the shared objective of the field is to stabilize and coordinate exchange, membership in networks and compatible practices". Zietsma et al. do not, however, expand on any specificities of the exchange field as opposed to the issue field, nor do they discuss potential overlaps between these two types of fields or how the two interact. Beckert (2010, p. 609) also conceptualizes markets as fields, "constituted and demarcated from one another by the mutual orientation of actors towards each other". Though he usefully draws attention to the dynamics of competition and power positions, by equating a market with a field Beckert's conceptualization arguably remains devoid of any specific reflection on the structuring force of the exchange on actors and their practices.

\section{The Market as not-quite-a-field}

In marketing, meanwhile, an increasingly voluminous set of studies has benefitted from institutional thinking to explore the creation, perpetuation, and disruption of values, norms, and exchange practices in markets (e.g.; Ertimur \& Coskuner-Balli, 2015; Hartmann et al., 2018; Humphreys, 2010; Rosa et al., 1999; Scaraboto \& Fischer, 2013). In contrast to the field literature summarized above, these streams of literature have put the exchange at the center of their attention, though with different emphases depending on researchers' specific conceptual leanings.

As briefly mentioned, market systems dynamics and SDL researchers both see markets as social systems populated by different sets of actors and buttressed by institutions that are relatively stable but can be changed through actors' efforts. Where the latter researchers have considered these systems predominantly with a view to value co-creation (Frow et al., 2016; Hartmann et al., 2018; Vargo et al., 2017), the former have often focused on the (de-)institutionalization of norms, values, and logics. Humphreys (2010) for instance was one of the first to draw attention to dynamics that are exogenous to markets by studying how markets arise out of the social fermentation of framing and legitimation. The 'outside' of the market, in her account, provides the "relevant cultural, social, and legal fabrics that open gaps for new markets and provide resources for the establishment of a new industry" (ibid. p. 1). She demonstrates through the emergence of casino gambling how actors spun their networks across broader organizational fields, which they 
also used to frame and legitimize the emergent market. Similarly, Dolbec and Fischer (2015) focus on the work done by market actors (fashion-conscious consumers in their case) outside of the market in influencing market dynamics such as the emergence of new categories of actors and products. They lean on Bourdieu's field theory to investigate the different logics that influence consumers, which may stem from diverse fields and are only imperfectly reproduced in the market in question. Their market actors are simultaneously institutional actors who ensure the continuation of field-level institutions on which the market draws.

In many other cases, such institutional entrepreneurship can be disruptive to extant market structures, as was the case of the 'Fatshionistas' in Scaraboto and Fischer's (2013) account who challenged the market's commercial logic with the logic of art. Institutional logics also stand at the core of Ertimur and Coskuner-Balli's (2015) interest in exploring the evolution of the Yoga market in the U.S., which they explain as sustaining a careful balance of multiple logics emanating from separate fields including healthcare, spirituality and sport. Thus, this set of authors clearly recognizes that for markets to emerge and/or evolve, market actors draw on something that is external to the market, including norms, institutions, logics and frames. While being clear that markets emerge out of a social, cultural and institutional fabric that pre-exists them, they stop short of zooming in on the movements and cross-fertilization between market and field. One of the rare studies that focuses on how actors migrate between the market and the field is Kjeldgaard et al.'s (2017, p. 55) case of Danish beer enthusiasts who morphed from "enthusiastic consumers to powerful field actor" by engaging in collective action, going back and forth between the market and the field.

Market studies researchers, meanwhile, see norms, power relations, or boundaries not as structural givens but rather as created and maintained through specific practices and their material manifestations (Bajde, 2013). Accordingly, Nenonen et al. (2014, p.271) define markets as "ongoing socio-material enactments that organize economized exchanges". From this perspective, topologies of social structures are never assumed but always made by specific practices of specific actors-it is 'actors all the way up', to paraphrase Latour (2005). These actors can-at least partlybe material. Moreover, where in institutional accounts market actors attach themselves to pre-existing logics, critical market studies researchers are much more interested in 'what's valuable' or 'what's at stake' to diverse sets of market actors, and how different answers to these questions are manifested through socio-material practices and market infrastructures.

From a Callonian (1998) standpoint, by disentangling actors and objects from attachments to the 'outside', markets become one big calculative space, enabling exchanges through exclusions; though doing so takes considerable and continuous effort. The question of the market's 'outsides' thus becomes one of tracing multiple actors' attempts at framing markets to facilitate or contest exchange. Critical market studies researchers acknowledge the fact that actors never completely shed their connections to other (non-market) roles and relationships. Similar to 'issues' in the studies on fields, 'collective concerns' can find their way into markets, particularly when actors aim to contest the current answers the market gives to the question of 'what's at stake' (Frankel et al., 2019; Geiger et al., 2014). Market boundaries thus become "dynamic, porous and contentious"-they are forever made and remade (Finch \& Geiger, 2010a, p. 241). Geiger and Gross (2018) for instance describe the case of a civilsociety driven pharmaceutical patent pool that acts as an activist tool 'inside' the market, to use the authors' words, by drawing issues from 'outside' the market into its calculative apparatus. As a market device, the activist tool repositions market actors in relation to the exchange by altering the terms of competition in this particular market. In addition, by claiming a stake in the exchange, civil society actors themselves become market actors. In a similar vein, Doganova and Laurent $(2019$, p. 223) trace "the distribution of issues across different domains" (in their case policy and the market) through boundary making in EU environmental markets. These studies and others show that for market studies, "efforts to shape markets" and their boundaries and "efforts to operate in markets qua structures" (Araujo et al., 2008, p. 8) are intrinsically interlinked to those concerns, stakes, and structures that linger 'outside' the market.

In summary, institutional field literature has recognized that agglomerations of actors may form around issues-or debates that attract concerned actors. Market systems dynamics and SDL scholars have shown how some such issues may be brought into markets by different sets of actors and affect the way in which valuecreation and economic exchanges happen in markets. Critical market studies have specifically focused on the concerns that are excluded from, or overflow, the market's boundaries and how they can be 'picked up' by field actors, debated, and eventually brought back into the market. There is thus a recognition implicit across these sets of literatures that markets and their 'outsides' are inseparable and often populated by the same (though multiple and diverse) sets of actors. This makes it analytically challenging to determine where one starts and the other ends. Questions remain as to how markets and their 'outsides' relate; whether actors belong to one or both at the same time, and how issues (or concerns or stakes) flow out of one and into the other. Our next section will address these questions in more detail. 


\section{How stake-making helps to map boundaries between fields and markets}

Based on the preceding review, in this section we posit identity/positions and issues/exchange as the two boundaryconstituting elements between field and market and we delve in more detail into these two interrelated boundary pairs. However, we also acknowledge that field and market boundaries are actively maintained and questioned by the actors themselves, with the nature of that work depending on the inherent multiplicity of fields and markets and particularly on the inclusion and exclusion of actors (Doganova \& Laurent, 2019; Ellis \& Ybema, 2010; Finch \& Geiger, 2010a; Zilber, 2011)

Let us turn first to the issue of membership-or the question of how an actor becomes part of a field or a market. Simply put: because markets are structured, if an actor wants to be a 'member' of a market, they will have to slot into relatively well-defined roles that position them in relation to the exchange. By contrast, fields, in which actors relate to issues, do not confer positions as much as they confer identity-and by extension a much looser form of membership (Patvardhan et al., 2015). In markets, actors take up their positions in relation to the exchange: actors become buyers, sellers, intermediaries, governors, or critics of the exchange based on the way in which they relate to it. While often thought of in terms of positions that are focal to the exchange-buyers, sellers, intermediaries and so on-it is important to note that actor positions can extend to roles such as governor or challenger, and actors themselves can create new positions or challenge existing ones (Geiger \& Finch, 2009). Once established, taking up a position vis-à-vis the exchange ties market actors at least temporarily into attendant affordances and limitations on their ability to frame new ideas and mobilize resources (Sgourev, 2013). Actors who command dominant positions within a market structure thus gain access to power and prioritized information (Davis \& Greve, 1997; Fligstein, 1996), which in turn better equip them to defend against those who might question prevailing enactments of the market. Incumbents will resist any threat to alter these positions that might reduce or remove their scope to act. New market actors must thus engage in a substantial reframing of the market in order to gain their own abilities to act (Dubuisson-Quellier, 2013; Gurses \& Ozcan, 2015). Thus, where institutional theory sees markets as structures with relatively stable formatted positions, market studies would emphasize the fact that they are only ever a temporary stabilization of actors' jostling for abilities to act.

By being constituted around an issue, fields confer identity more than they confer positions (though the literature recognizes field centrality and fragmentation as broad positional features). Zilber (2011) describes how the charting of field boundaries constructs the identities of players and interests within a given field. The field "provide(s) individuals with a vocabulary of motives and a sense of identity and generate(s) values and prevailing concepts of organizational work and worth." (Oakes et al., 1998 p. 261). Thus, fields are constituted through mutually reinforcing boundary work and identity work (Zietsma \& Lawrence, 2010). Identity work establishes and revises the boundaries of the field, signaling and determining who is in or out, and boundary work in turn confers field identities: "It is the very charting of boundaries that constructs the field as containing multiple players, discourses, and interests, a complex and varied network of interdependencies, tensions, and intermediates." (Zilber, 2011 , p. 1555). The fact that Israeli high tech was characterized by diversity in terms of actors (from start-ups to multinational firms, venture capitalists to regulators), geographies (Israel, the United States, Europe, and the Far East), and understandings as to what Israeli high tech is all about (from hypermodern technological enterprise to capitalist, global, and national projects) did not detract from Israeli high tech being conceived of as a single field (Zilber, 2011).

Based on identification rather than position, field membership is potentially more fluid and field actors' orientation towards the issue may involve less commitment than market actors' positioning vis-à-vis the exchange. Even in consumer markets, where some actors can just move in and out of the market at will, each consumer must at a minimum commit to a financial outlay in order to engage in the exchange. In recent times, on the other hand, social media practices involving little commitment such as re-tweeting or changing a profile picture epitomize such low-cost membership in social movement fields, including in healthcare (Moran \& Mountford, 2021). Both involve low effort advocacy activities such as changing a profile picture on Facebook or Twitter, demonstrating involvement at little cost to the participant (Zuckerman, 2014). This drawing into the field of very diverse sets of actors may not be permanent but depends on the ongoing relevance of an issue to those actors. The resolution of the issue may release an actor from field membership as they no longer need to engage with other actors within that field (Hoffman, 1999).

Our second boundary-constituting element revolves around the question of 'what is at stake' and how these stakes are made to count. We argue that in fields, actors claim or make stakes through their relating to and framing of the issue, whereas in markets, actors claim a stake in and through relating to the exchange. To understand this point, it is important to note that issues in fields and exchanges in markets are likely to be contested, with 
'truces' or settlements as temporary states of stability. In relation to fields, institutional researchers have studied how actors 'frame' issues or "make some aspects of an issue more salient to other field actors in order to attract their support" (Furnari, 2018, p. 328). 'Issue contests' (Gurses \& Ozcan, 2015) happen when different (groups of) actors rally for other actors' support of their particular framing of what is at stake in a particular field. To illustrate this process, Hoffman's (1999) chemical field moved from a state where the chemical industry all but denied any impact of their activities on the environment to collaborating with NGOs over solutions to chemical pollution. This reframing of the stakes in the field swept over into the policy field by influencing regulation and legislation, and eventually the issue was brought into the market through regulation, which triggered an innovative reshuffling of the exchanges in the chemicals market (see also Finch et al., 2017a, b).

When, as in this example, actors take up a position in relation to the exchange, they translate their concerns or issues into the market's calculative space. Institutional theory recognizes this transformation as one where market actors must position themselves vis-à-vis a market logic (though see Fligstein \& McAdam, 2012 for a criticism of institutional logics in field studies). In her study of the rise of market capitalism in higher education publishing, Thornton (2002) for instance theorizes that because logics structure actor attention in organizations, conflict amongst different institutional logics will drive change, "focusing the attention of decision makers toward those issues that are consistent with the logic... and away from those issues that are not" (p. 97). This shifting of attention may alter the organization of the economic exchange and, relatedly, actors' abilities to act toward it. The introduction of a market logic into a field may give rise to a market that is embedded within the field and, as the market logic gains traction, more and more actors may find themselves holding dual membership of both market and field. From a market studies perspective, the emphasis on logics in institutionalism yields to the more hands-on way of stakemaking, where actors aim to influence the calculative apparatus and abilities of other actors when they bring their issues into a market. An example is given by DubuissonQuellier's (2013) analysis of the 'little green book'. This market device, published by a non-governmental organization, enabled consumers to make more environmentally conscious choices by broadening the issues associated with the purchase of groceries. Importantly, it did not simply bring an 'environmental logic' into the market, but it also equipped the consumer-actor to perform different calculations (taking food miles into account, for instance) while shopping, which had material effects on the market's setup.

\section{The relationships between markets and fields}

To summarize our argument thus far, we agree with authors such as Zietsma et al. (2017) that fields form around issues while markets form around exchanges. However, we see a key difference in the way in which actors relate to fields and markets. Unlike a loosely bounded field that offers a landscape for action, a market acts directly to structure social interactions. Fields accommodate a palette of issues with actors identifying with the field through a commitment to the issue at the center of a particular field, whereas acting within a market structure necessarily requires positioning oneself in relation to the exchangeand thus buying or claiming a stake in the exchange. It is the combination of the market's positioning of actors and the centrality of the exchange that allows those who wish to engage in a market to find one another, to understand and agree on a pricing arrangement, and to complete transactions in the assumption that all parties will hold up their end of the deal (Fligstein \& Dauter, 2007). The focus on an issue within a field does not quite have the same structuring effect. It will attract or repel sub-populations who see themselves as affected by the issue or who regard the issue as irrelevant to them. Those for whom the issue is relevant see themselves as part of the field, those for whom it is not will see themselves as part of another field (though overlaps and peripheral membership are of course possible, and actors may also try to reframe issues to better reflect their concerns). While field membership may be encouraged by powerful actors (re)defining or framing the issue (Child et al., 2007), it seems impossible to enforce such membership beyond attraction or enticement. By contrast, an actor seeking to relate to a particular exchange is a de facto member of that market, even if only temporarily. The reach of the centrifugal force exerted by the exchange will ultimately determine the extension or contraction of the market to include field actors.

In summary, fields and markets both include a cornucopia of actors including producers, consumers, regulatory agencies, lobbying groups, unions, advocacy groups, and social pressure groups, but they relate differently when relating in a field or a market. The difference is that we only see these actors as part of the market once they take up a position in relation to the exchange. They may well exist on the stage offered by the field long before they become a part of the market structure. Thus, where Beckert's market field's boundaries are cultural and political in nature, ours are dictated by the relationship to the exchange. Our market straddles one or more fields, and actors from those fields may appear to move in or out of the market structure over time. As an aside, being 
bounded by the exchange also means that markets can draw members from multiple fields at once; while these diverse actors may bring different issues and answers to the question of 'what counts' into the market, the market, qua exchange, acts as a type of trading zone that facilitates coordination of interactions regardless of potential differences between actors (Finch \& Geiger, 2010b).

Figure 1 summarizes our actor-centered view of the relationship between markets and fields. Both conceptually and empirically the relationship between the two is shaped by the multiple sets of actors that are in the market, the field, or both. When individual and organizational actors see the issue and the exchange as unrelated-in other words that only one of them is 'at stake' for them-the market and field will remain separate. When actors make the issue or exchange 'count' in the market or the field respectively, these will overlap. Similarly, where an actor solely relates to other actors through positions vis-à-vis the exchange, or through their identity in relation to an issue only, the field and market remain separated for them. On the other hand, where their relationships to other actors are shaped by a combination of position and identity, the market and field will overlap. Because each organization and individual chooses what counts for them some will see market and field as overlapping while others will see them as distinct-to revert back to Hoffman's classic example, the chemical industry for the longest time saw itself as part of a market but not 'concerned' with the field of environmentalism. We argue that this in part accounts for the complexity in analyzing and conceptualizing market and field. In fact, actors will redefine both positions and identity, as well as what is at stake for them, over time (Mountford \& Geiger, 2020). There will, therefore, be multiple permutations and combinations of the

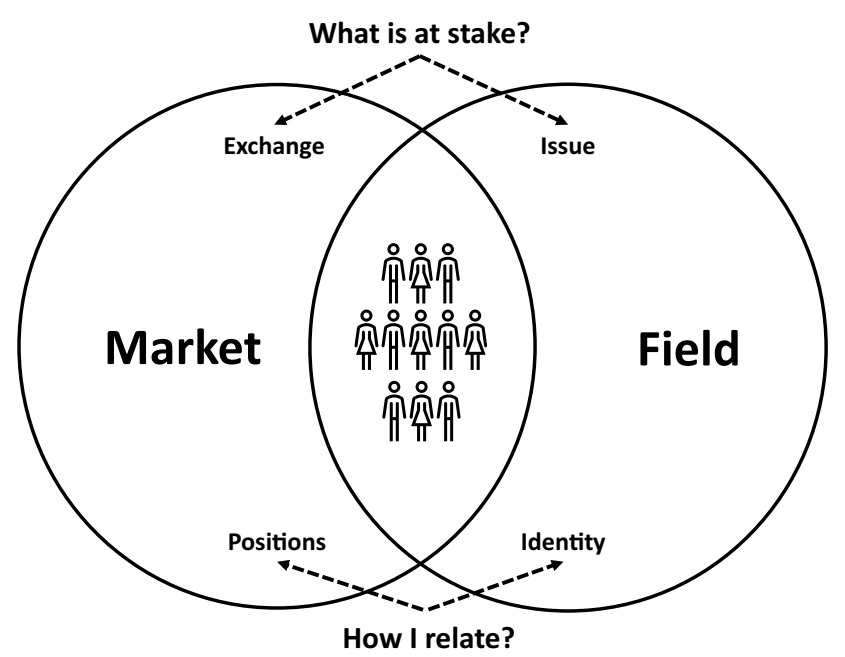

Fig. 1 An actor-centred view of the relationship between fields and markets relationships between markets and fields. We go on to suggest possible manifestations of these field/market re-configurations, offering four non-exhaustive illustrative examples of such relational shifts based on extant empirical accounts of market or field dynamics.

\section{A typology of market/field dynamics}

We see the relationships between field and market as inherently dynamic. Field actors and their issues will exert influence over the market, just as the market's exchange structure will re-configure actors' abilities to act, and in doing so, either challenge or reinforce field institutions. Above all, we argue that it is the actors' attention on the issue versus the exchange that will determine the respective spread of, and overlap between, field and market.

Rather than imagining 'vertical' boundaries between fields and markets or seeing the two in a hierarchical relationship, we propose a horizontal view of this relationship; actors do not "hop over" a field/market boundary as they would if it were vertical, but rather they retain their attachments to a field while migrating in and out of the market (and vice versa). It is this migration that influences the dynamics between field and market. Our layered view draws on Fligstein and McAdam's (2012) "Russian doll” perspective of multiple nested and overlapping fields as well as on the stacked nature of the market-field relationship assumed by Kim and Kogut (1996) over two decades ago. For them, knowledge to act in markets is "derived from experience with the underlying science and related technological fields" (p. 283). Extrapolating from this layered model, we go on to discuss four different ways in which field/market dynamics might manifest by describing the overlap between these layers and how one layer exerts a force on the other. These four are, of course, not exclusive, and hybrids of these dynamics may exist in addition to dynamics that are not captured here.

\section{Market as field mirror}

In this market/field dynamic, the market is stretched to accommodate ever-widening membership to a point where it almost completely embraces the field population. An issue-laden or 'concerned' market (Geiger et al., 2014), although still centered around exchange, will increasingly overlap with the field(s) in which it sits. Field actors, who initially identify themselves in relation to the issue, begin to see the exchange as central to that issue. Their focus therefore becomes attracted by both issue and exchange, and they begin to take up positions vis-à-vis the exchange-for example as regulators, active non-consumers, or exchange-related social movements. As per Hoffman (1999), the US chemical market of the 1960s was focused on the buyers and sellers 
of chemicals. The publication of the book Silent Spring (Carson, 1962) focused actor attention on the environmental issues associated with this market. Chemical manufacturers soon found themselves in dialogue with "government agencies, scientific organizations, and conservation groups" as these groups began to focus on the production and exchange of chemicals (ibid. p. 352). Over time, actors who identified with the environmental field also started to influence the regulatory landscape. Regulation for 'green' chemistry, in turn, significantly influenced the production and exchange of chemicals, infusing the market with new calculative abilities and leading to a reshuffling of actor positions (Finch et al., 2017a). Thus, in this case actors who were initially focused on environmental issues now held the chemicals market in their gaze too, with issue and exchange becoming two sides of the same coin: "what were previously environmental issues-recycling and water treatment-were now being covered as mainstream chemical industry market niches" (Hoffman, 1999, p. 364). It should be noted that as market overflows are seized upon by actors, there is always a possibility of a new issue field becoming 'visible' beyond the market.

Proposition 1: Where field actors successfully harness the market in service of their issue, the overlap between field and market actors will increase to a point where market and field may appear to be one and the same.

\section{Field as Market Mirror}

In the opening stage of this market/field dynamic, actors from a number of different fields come together around an exchange. Their single common point is the exchange itself and within that market they are defined only by their position vis-à-vis the exchange-they are producers, purchasers, distributors etc. Any issues that attract their attention sit within separate issue fields with which they identify. Over time, however, actors' attention begins to focus on common issues and they begin to add a common identity to their market positions as they take up positions vis-à-vis those issues.

Aspers and Darr (2011) describe a situation where, in its early days, the emergent real time computing market drew upon actors and practices from a variety of fields including electrical engineering, the military, computing, and others. Clients were typically very large corporations as these had deep enough pockets to fund the collation and customization process involved in bringing these elements together. Initially, the focus of these clients and each of the constituent producers was solely on the exchange at hand and playing their part in it. This, therefore, was the initial real time computing market. Those who chose not to partake in this market had their focus on issues (or what Aspers and Darr call uncertainties).
For instance, the fact that the military was a large producer and consumer of the initial real-time computing market led some to be concerned about "the identity and qualities of prospective buyers, and an uncertainty about the desired use, or application, of the innovative products produced by small engineering firms in a craft-like production mode" ( $p$. 759). Through concerted efforts of a handful of actors organizing trade shows known as the 'Traveling Circus', a new field of real time computing soon began to coalesce around the addressing of these issues. Actors from diverse fields redefined themselves in relation to the exchange in order to build a collective identity and reduce concerns related to the customers' identities and the products' valuations. As the market's boundaries solidified through this clearer positioning of market actors and products, so did the new field's, and actors began to see themselves as members of a single field: "it is the practical interaction of humans ... who are tied to organizations and who engage in daily boundary work which constitute the baseline of markets and then industry" (p. 767). Beyond the structures of exchange and competition in the real time computing market, this boundary work, triggered by a need to address exchange-related issues, created social bonds based on "the constitution of collaborative networks and trust" (p. 776), and facilitated the emergence of shared norms and practices.

Proposition 2: Where market actors from different fields identify a common issue or set of issues and address these over time, they will form a new field that echoes the membership of the original market but includes a focus on issues as well as exchange.

\section{Field fragments along market lines}

This dynamic sees an established field fragment into multiple fields that echo multiple existing or emergent markets. In this process of field partitioning, actors develop and embrace distinct identities, boundaries, and infrastructures, echoing Faulconbridge and Muzio's (2019) conceptualization of field partitioning "as a multi-stage process involving the following mechanisms-focusing on new opportunities, inter- and intra-subfield networking and distinction" (Faulconbridge \& Muzio, 2019 p. 2). In our "Field fragments along market lines" dynamic, subfields develop as field actors cohere around an exchange. As mentioned previously, markets, being inherently abstract, are only enacted when actors take up a position in relation to a commercial transaction.

Granqvist and Ritvala (2016) provide an example of field fracturing in their study of the field of nanotechnology in Finland. Government, for funding and innovation policy purposes, construed nanotechnology as activities in the size scale of $1-100 \mathrm{~nm}$. Individual and organizational actors, from scientists 
to start-ups to multinational enterprises, gathered around this definition in an emergent field in order to address their common issue of access to funding. Over time, this gave rise to a field of nanotechnology wherein actors defined themselves in relation to the policy issues of nanotechnology. While doing so, however, many continued to produce the same products and service for the same markets that they always had, taking up positions as suppliers/producers (of knowledge or products), consumers or providers within these diverse markets. This positioning of actors in much narrower and better-defined markets made it clear that the "the general definition of nanotechnology as activities in the size scale of $1-100 \mathrm{~nm}$ did not provide sufficient boundaries for the field, and boundary drawing became a political process driven by varying interests" (p. 225). Once funding concerns started to subside, actors "lacked sufficient similarity and cohesion" (p. 226) to continue to be considered a field of nanotechnology. In other words, while identification as a 'nanotechnology' field actor was made possible through the promotion of an issue ("funding and growth"), the producers, buyers and sellers involved did not see themselves as linked by a single issue once funding ceased to be an attractor. Actors found it all but impossible to position themselves as a nanotech company in an exchange (see also Granqvist et al., 2013). This "led to an understanding [among companies] that it is an enabling technology forming part of the production process within several market categories" (p. 229). As actors focused on different issues linked to their activities in narrower markets, the field splintered along narrower market lines.

Proposition 3: Where loose field composition hinders actors' ability to engage in market exchanges, actors may create multiple smaller fields focusing on narrower issues that are more closely related to the exchange.

\section{Market fragments along field lines}

Field actors such as social movements may focus on particular market niches as commercial spaces that can accommodate their issues. In doing so, they can catalyze a process where issue and exchange align and the niche solidifies into a market in its own right. Weber et al. (2008 p. 538) demonstrate how the grass-fed meat and dairy movement drew from a field-level repertoire of codes to establish binary oppositions between "the insurgent domain of grass fed production, marked positively as an affirmation of moral values, and the domain of the incumbent industry system, marked negatively as a violation of moral values." As recently as the early ' 90 s the term 'grass-fed' referred only to a method of production within the field of agriculture and had little impact or resonance on the multiple beef and dairy markets that it serviced. In the late ' 80 s and ' 90 s however, actors, including those with no stake in the exchange of beef or dairy products such as journalists and food writers, gathered around issues such as "sustainable land management, the consumption of local food, fair trade, and "slow food"' (p. 534). This field-level work, over time, served to fragment the dairy market through building two distinct exchange systems which served to strengthen both the market's definition and appeal and the cohesion of the underlying sub-field. By 2008, grass-fed meat and dairy products were being "sold at a premium by ranchers, health food stores, and large specialist retailers such as Whole Foods" (p. 533) while references to 'the grass-fed industry' became common in news outlets.

Proposition 4: Where market actors see that a field issue may carve out a lucrative and defensible exchange opportunity, they may narrow their market position to focus on that opportunity, thus identifying with the issue and becoming part of that field population.

Table 1 A Research Agenda for Market and Field Dynamics

\begin{tabular}{ll}
\hline Research Agenda \\
\hline Conceptual & Conceptualize the continuum of market/field relationships from those that are relatively clear-cut to those \\
& that are more blurred. \\
& - Consider the contextual impact of market/field relationships on lifecycle issues, particularly market/field \\
& emergence and demise. \\
& - Consider interactions or overlaps between position and identity. \\
& - Identify key market positions vis-à-vis the exchange. \\
& - Link actor positions to relevant issues. \\
& - Map relationships between market and field in terms of relative actor interest to the exchange vs the issue. \\
& - Trace actor and issue movements over time. \\
- Study how non-market actors relate the issue to the exchange. & - Establish the role of market/field interactions in the dissolution or reincarnation of markets and/or fields. \\
& - Follow how valuation practices and devices migrate between markets and fields. \\
& - Leverage empirical insights to explain market power, inclusion and exclusion. \\
\hline Empirical &
\end{tabular}




\section{Toward a research agenda}

We have conceptualized the relationship between markets and fields and offered examples of these relationships, illustrating these with reference to the literature. We now build upon this to propose a research agenda for those who seek to understand and leverage the inter-related nature of markets and fields methodologically, analytically, or empirically. In doing so we set out a tri-partite research agenda, as summarized in Table 1 below.

\section{A conceptual agenda for markets and fields research}

With this paper we have begun to conceptualize the distinctions and relationships between markets and fields. There remains, however, considerable work to be done in refining and testing this conceptualization. In particular, we have presented four illustrative relationships between the two constructs. For the purposes of this paper and to open up conceptual debate we have simplified these relationships. As we have acknowledged, the relationships between markets and fields are often likely to be considerably less well-defined than our examples may suggest. Researchers should therefore work to examine both more, and less, clear cut market/ field relationships. Hybrid economies, for example, may offer examples of markets that seem less market-like. The focal point-the exchange-may not be as clearly demarcated as in other markets, and market positions and characteristics that normally define these positions (as per the section above) may be less present (Chimenti, 2020; Eckhardt et al., 2019). Are these markets more like fields, and if so, what does this tell us?

An enduring question both in the fields and markets literatures is that of diagnosing and explaining lifecycles. While it is not within the remit of this paper to fully address these questions, we posit that the relationships between market and field may be helpful in contextualizing such research going forward-particularly with regard to market or field emergence and demise. From an emergence perspective our framework offers a window into how new fields or markets may 'reach into' existing fields or markets for structure and legitimacy. Actors seeking to create nascent markets may draw on one or more fields to facilitate and organize exchanges-in Humphreys' (2010) example of the market emergence of casino gambling, organizations drew heavily on the broader field's regulative, cognitive, and social processes for legitimation and expansion. Reciprocally, actors within a weakly institutionalized (emergent or recently unsettled) field may deliberately develop a (proto-) market in order to provide a level of stability to the "underlying' field. The structured positions and boundaries of the exchange relationship may help to organize contestation of an emergent issue. Our layered perspective may also be particularly helpful in explaining the heretofore neglected topic of market demise. In Zietsma et al.'s (2017) theorization, an issue field may transform into a market (or an exchange field as they term it) and vice versa, which would explain the disappearance of one to the benefit of the other. From our perspective, it is more likely that, as long as an issue field persists, exchange structures (or markets) will form that buttress that field. However, it could be possible that one such structure takes over from another, with the latter becoming defunct or dissolving completely. We see this in areas where networks take over market functions such as price setting or distribution-as for instance in Pressey et al.'s (2014) case of successful cartels-but there are other examples of market demise that could fruitfully be explored. In Zelizer's (1994) famous account, for instance, the removal of children from the labor market gave rise to markets in children's life assurance. Thus, research should examine empirical cases of market and field dissolution and reincarnation to further help conceptualize the relationship between the two realms, and vice versa, take account of this relationship in analyzing and explaining market or field lifecycles.

We have further posited that in markets actors take up their position vis-à-vis the exchange while in fields, actors take account of each other through their identification with or against an issue. Market roles can, however, also carry with them a sense of identity. For example, entrepreneurs hold a production-related role in relation to the exchange within the market; but they may also see themselves as entrepreneurs quite apart from their exchange-related role, especially in areas such as emancipatory or 'unconventional' entrepreneurship (e.g. Guercini \& Cova, 2018). Does this mean that there is a 'field' of entrepreneurship where they identify with an issue (perhaps the need to sustainably innovate) that overlaps with the market? Or can the market hold both exchange-related roles and issue-related identities at once? This question should be addressed in the next phase of conceptualization of the market/field relationship, answering Weber's question as to how "individual producers establish a collective identity that forms the basis of internal community and external differentiation" (Weber et al., 2008, p. 530).

In this paper we followed Hoffman (1999) in using the issue as an anchoring construct within the field, and much of our theorizing revolves around the relationship that actors have with the issue as compared with the exchange. There is, however, a remaining question as to how markets and their actors relate to fields other than issue fields, for example organizational fields or policy fields. In these fields what is at stake may vary widely and the impact on the market may therefore differ considerably. In addition, actors may leverage their relative strengths from these diverse fields when moving into a market position and vice versa. These market positions may offer considerable leverage in one type of field while being of negligible importance in another (see 
Evans \& Kay, 2008). Of particular interest here are 'interstitial' positions-that is, actors located within structural folds and overlaps-who may become particularly influential in precipitating field and/or market change (Furnari, 2014; Mountford, 2019; Vedres \& Stark, 2010). The relationships between different types of fields and potentially, different types of markets, will therefore depend on a complex array of links and impacts between what is at stake in those fields and the exchange. Future research should build on our preliminary framework to conceptualize a more complex 'architecture' (Evans \& Kay, 2008) of fields and markets than the one we presented here.

\section{A methodological agenda for markets and fields research}

How should researchers go about identifying and analyzing the links between markets and fields? We began this paper by defining a field relationally, as a set of actors who take one another into account in a social arena with an issue at stake. Rather than considering markets to be exchange fields (as per Zietsma et al., 2017), we see markets as socio-material structures where the 'stake' is clear-it is the actors' position in the market and their ability to defend that position against attempts to reshape the market's structures and practices. When we apply this lens to the study of the overlap or relationship between market and field, it becomes clear that, of the two, the market offers the clearer template for the identification-or as we call it, positioning-of the actors within its social arena. Researchers should, therefore, begin by mapping the types of market position available within their study-consumers, providers, regulators, intermediaries, influencers etc.-and trace the relationships between these positions as well as their relationship to the exchange. Once identified, holders of each position in a particular market can be analyzed and from these, researchers can identify the issues that each position or specific holder connects to-in other words, mapping what is at stake for these market actors beyond the exchange. These issues can then be traced into their respective fields and linked to non-market actors who also have a stake in this issue, albeit not in the exchange that sat at the heart of the original market. As positions move further away from the exchange they are likely to become more peripheral to the market and more likely to be captured by issues within nearby fields. Of course, such mapping may also be conducted in the other direction-from field(s) into markets. Such mapping would lend itself particularly well to longitudinal research considering the dynamics between markets and fields, tracking actor and issue movements at specific points in time and over time.

\section{An empirical agenda for markets and fields research}

Our conceptualization and typology begin to provide templates for empirically tracing the movements and interactions of actors between markets and fields. It is vital that researchers of markets take account of the 'outsides' that market actors also inhabit (such as in our case the field). Such study should also consider what may motivate, or indeed compel, field actors to get involved with the market's exchanges. For example, why and how do social movements create and exploit potential conflicts and/or complementarities between issue and exchange? What is the reciprocal nature of such actions on the market/field relationship and vice-versa? The exchange/issue inter-relationship becomes less clear and therefore requires more theoretical investigation as market actors take up a stance vis-à-vis issues such as racism but 'endogenize' the issue within the market. One example is the many advertising campaigns that surrounded the Black Lives Matter movement. This may offer greater understanding as to why and how market actors strategically become involved with certain issues. Likewise, there are empirical cases where traditionally non-market actors utilize the market's infrastructures and informational regimes for the purpose of influencing institutional meanings at the field level-for example where non-paying patients and their families (who previously played no active role in the exchange), use the drug reimbursement assessment process to challenge institutionalized conceptions of value (Moran $\&$ Mountford, 2021). Do such actors merely use the market within a field to 'win' the issue or are they taking up new positions within the market in relation to the exchange? When such crossovers occur, how is agency affected within the market? Under what conditions do market actors manage to retain agency? For example, where can they use their technical nous and material infrastructure to "technologically capture' their regulators as per Finch et al. (2017a, b) and when might such agency evaporate in the face of field overlap and the greater drive towards issue rather than exchange?

The empirical mapping of such boundary crossings will help address a vital aspect of the study of markets: their power (im)balances, exclusions, and inclusions. Cova et al. (2021) have recently tackled this important issue through a typology of market exclusions. They acknowledge that actors only ever partly 'live' in markets and thus exclusion from a market does not preclude that same actor from holding a position of power in another social arena. Empirical study of such multiple structural existences will better illuminate how markets may become more inclusive in their own right. Such studies may also demonstrate how excluded actors migrate to and/or create alternative social structures through which to interact and exchange. Researchers may wish to empirically follow the specific stakes that are excluded from markets into 
these other social arenas, including issue fields as focused on within this paper.

A final but nonetheless crucial area for empirical work revolves around one of the most pressing concerns in research on markets over the past ten years: to explain what is considered valuable in markets, and how this value is created, shared, and contested (Brodie et al., 2019). Research has shown through many empirical examples that market value is often a fragile achievement of "artful compromising" (Finch et al., 2017a, p. 89). We suggest that there is significant conceptual value in empirically distinguishing between the market's exchange and the field's issues in tracing the provenance, interaction and impact of diverse values, valuation and value co-creation practices, particularly considering the dual existence we claim for our field/market actors. Frow et al. (2016) provide the hypothetical example of a group of scientists, which in our model would be situated at the field level, jointly speaking out against a specific health care practice, such as the use of a specific drug, which would cause the disruption of established exchange practices in the market. From a market studies perspective, Moran and Mountford (2021) similarly show how patient organizations successfully challenge the Government's decisions as a market regulator, with knock-on effects on how value is perceived and shared in the pharmaceutical market. While SDL researchers have started to include these more macro concerns into their service ecosystems perspective, we would encourage a more overtly 'political' reading and mapping of valuation flows, practices, and challenges between markets and fields, This may also be an avenue to bring into conversation the three main bodies of literature in marketing that are concerned with markets: the 'value creation' oriented SDL, the 'values' oriented market systems perspective, and the 'valuation' oriented market studies.

\section{Conclusion}

This special issue sets out a path towards a theory of markets. We argue that conceptualizing the relationship between markets and fields will help such theorization on several counts. First, it will allow broad comparison between studies on markets emanating from different conceptual and empirical traditions, most importantly the institutionally oriented market systems dynamics tradition and the market studies domain. Second, a simultaneous focus on fields and markets-and the shifting dynamics between them-will allow researchers of markets to be clearer about how the 'outsides' and the 'inside' of a particular market interact. While we have chosen to focus our conceptualization on the issue field, we wish to reiterate that there are manifold such 'outsides', and many of these are in constant interaction with the markets we study. We acknowledge that this simultaneous focus may represent an empirical challenge in bounding a specific study; to researchers faced with this problem we provide some methodological ideas of how to trace actors and their concerns across markets and field. There remains much work to be done to theorize markets, their boundaries and the spaces abutting their boundaries. Given the ever-increasing dominance of the market in society, the ability to distinguish between and inter-relate these two concepts has never been more crucial. We hope that our contribution goes some way to facilitating such discussions.

Acknowledgement The authors would like to thank Professor Hans Kjellberg and Dr. Riikka Murto for their editorial guidance, and the anonymous reviewers for their insights and feedback throughout the review process. We would also like to acknowledge the generous comments of Professor Santi Furnari on an earlier draft of this paper. Our thanks also to the participants of the EGOS 2019 Sub-theme 57: Organizational Fields of the Future and the Future of Fields: Interactions, Intersections and Interfaces across Organizational Fields for their questions, comments and suggestions. Prof Susi Geiger gratefully acknowledges the support of the Horizon2020 ERC grant 771217 while working on this paper.

Funding National University of Ireland Maynooth. Open Access funding provided by the IReL Consortium.

Open Access This article is licensed under a Creative Commons Attribution 4.0 International License, which permits use, sharing, adaptation, distribution and reproduction in any medium or format, as long as you give appropriate credit to the original author(s) and the source, provide a link to the Creative Commons licence, and indicate if changes were made. The images or other third party material in this article are included in the article's Creative Commons licence, unless indicated otherwise in a credit line to the material. If material is not included in the article's Creative Commons licence and your intended use is not permitted by statutory regulation or exceeds the permitted use, you will need to obtain permission directly from the copyright holder. To view a copy of this licence, visit http://creativecommons.org/licenses/by/4.0/.

\section{References}

Ahrne, G., Aspers, P., \& Brunsson, N. (2015). The Organization of Markets. Organization Studies, 36, 7-27.

Anand, N., \& Peterson, R. A. (2000). When Market Information Constitutes Fields: Sensemaking of Markets in the Commercial Music Industry. Organization Science, 11, 270-284.

Araujo, L., Kjellberg, H. \& Spencer, R. (2008). Market Practices and Forms: Introduction to the Special Issue. Marketing Theory 8(1): 5-14.

Aspers, P., \& Darr, A. (2011). Trade shows and the creation of market and industry. The Sociological Review, 59, 758-778. 
Azimont, F., \& Araujo, L. (2007). Category reviews as market-shaping events. Industrial Marketing Management, 36(7), 849-860.

Bajde, D. (2013). Consumer culture theory (re) visits actor-network theory: Flattening consumption studies. Marketing Theory, 13(2), 227-242.

Beckert, J. (2010). How Do Fields Change? The Interrelations of Institutions, Networks, and Cognition in the Dynamics of Markets. Organization Studies, 31, 605-627.

Brodie, R. J., Löbler, H., \& Fehrer, J. A. (2019). Evolution of servicedominant logic: Towards a paradigm and metatheory of the market and value cocreation? Industrial Marketing Management, 79, 3-12.

Callon, M. (1998). An Essay on Framing and Overflowing: Economic Externalities Revisited by Sociology. The Sociological Review., 46(1), 44-269.

Child, J., Lu, Y., \& Tsai, T. (2007). Institutional entrepreneurship in building an environmental protection system for the People's Republic of China. Organization studies, 28, 1013-1034.

Child, J., \& Rodrigues, S. B. (2011). How Organizations Engage with External Complexity: A Political Action Perspective. Organization Studies, 32, 803-824.

Chimenti, G. (2020). Conceptual controversies at the boundaries between markets: the case of ridesharing. Consumption Markets \& Culture, 23(2), 130-153.

Cova, B., Ivens, B. S., \& Spencer, R. (2021). The ins and outs of market shaping: Exclusion as a darkside? Journal of Business Research.

Davis, G. F., \& Greve, H. R. (1997). Corporate elite networks and governance changes in the 1980s. American journal of sociology, 103, 1-37.

DiMaggio, P. J., \& Powell, W. W. (1983). The Iron Cage Revisited: Institutional Isomorphism and Collective Rationality in Organizational Fields. American Sociological Review, 48, 147.

Doganova, L., \& Laurent, B. (2019). Carving out a domain for the market: boundary making in European environmental markets. Economy and Society, 48(2), 221-242.

Dolbec, P. Y., \& Fischer, E. (2015). Refashioning a field? Connected consumers and institutional dynamics in markets. Journal of Consumer Research, 41(6), 1447-1468.

Dubuisson-Quellier, S. (2013). A market mediation strategy: How social movements seek to change firms' practices by promoting new principles of product valuation. Organization Studies, 34(5-6), 683-703.

Eckhardt, G. M., Houston, M. B., Jiang, B., Lamberton, C., Rindfleisch, A., \& Zervas, G. (2019). Marketing in the sharing economy. Journal of Marketing, 83(5), 5-27.

Ellis, N., \& Ybema, S. (2010). Marketing identities: Shifting circles of identification in inter-organizational relationships. Organization studies, 31, 279-305.

Ertimur, B., \& Coskuner-Balli, G. (2015). Navigating the Institutional Logics of Markets: Implications for Strategic Brand Management. Journal of Marketing, 79, 40-61.

Evans, R., \& Kay, T. (2008). How environmentalists "greened" trade policy: Strategic action and the architecture of field overlap. American Sociological Review, 73(6), 970-991.

Faulconbridge, J. \& Muzio, D. (2019). Field partitioning: The emergence, development and consolidation of sub-fields. Organization Studies (forthcoming).

Finch, J., \& Geiger, S. (2010a). Positioning and relating: Market boundaries and the slippery identity of the marketing object. Marketing Theory, 10(3), 237-251.

Finch, J. F., \& Geiger, S. (2010b). Markets are trading zones: On the material, cultural, and interpretative dimensions of market encounters. In L. Araujo, H. Kjellberg, \& J. Finch (Eds.), Reconnecting Marketing with Markets. Oxford: Oxford University Press.
Finch, J. H., Geiger, S., \& Harkness, R. J. (2017). Marketing and compromising for sustainability: Competing orders of worth in the North Atlantic. Marketing Theory, 17(1), 71-93.

Finch, J., Geiger, S., \& Reid, E. (2017). Captured by technology? How material agency sustains interaction between regulators and industry actors. Research Policy, 46(1), 160-170.

Fligstein, N. (1996). Markets as Politics: A Political-Cultural Approach to Market Institutions. American Sociological Review, 61, 656-673.

Fligstein, N. (2001). The architecture of markets: an economic sociology of twenty-first-century capitalist societies. Princeton University Press.

Fligstein, N. \& Dauter, L. (2007). The sociology of markets. Annual Review of Sociology.

Fligstein, N., \& McAdam, D. (2012). A theory of fields. Oxford University Press.

Frankel, C., Ossandón, J., \& Pallesen, T. (2019). The organization of markets for collective concerns and their failures. Economy and Society, 48(2), 153-174.

Frow, P., McColl-Kennedy, J. R., \& Payne, A. (2016). Co-creation practices: Their role in shaping a health care ecosystem. Industrial Marketing Management, 56, 24-39.

Furnari, S. (2014). Interstitial spaces: Microinteraction settings and the genesis of new practices between institutional fields. Academy of Management Review, 39(4), 439-462.

Furnari, S. (2018). When does an issue trigger change in a field? A comparative approach to issue frames, field structures and types of field change. Human Relations, 71.

Geiger, S., \& Finch, J. (2009). Industrial sales people as market actors. Industrial Marketing Management, 38(6), 608-617

Geiger, S., Kjellberg, H., \& Spencer, R. (2012). Shaping exchanges, building markets. Consumption Markets \& Culture, 15(2), 133-147.

Geiger, S., \& Gross, N. (2018). Market Failures and Market Framings: Can a market be transformed from the inside? Organization Studies, 39, 1357-1376.

Geiger, S., Harrison, D., Kjellberg, H. \& Mallard, A. (2014). Being Concerned about Markets. In: Geiger, S., Harrison, D., Kjellberg, H. \& Mallard, A. (eds.) Concerned Markets. Cheltenham, UK: Edward Elgar Publishing Ltd.

Geiger, S., \& Kjellberg, H. (2021). Market mash ups: The process of combinatorial market innovation. Journal of Business Research, $124,445-457$

Giesler, M., \& Fischer, E. (2017). Market system dynamics. Marketing Theory, 17(1), 3-8.

Granqvist, N., Grodal, S., \& Woolley, J. L. (2013). Hedging Your Bets: Explaining Executives' Market Labeling Strategies in Nanotechnology. Organization Science, 24(2), 395-413.

Granqvist, N., \& Ritvala, T. (2016). Beyond prototypes: Drivers of market categorization in functional foods and nanotechnology. Journal of Management Studies, 53, 210-237.

Greenwood, R., \& Meyer, R. E. (2008). Influencing ideas: A celebration of DiMaggio and Powell (1983). Journal of Management Inquiry, 17, 258-264.

Guercini, S., \& Cova, B. (2018). Unconventional entrepreneurship. Journal of Business Research, 92, 385-391.

Gurses, K., \& Ozcan, P. (2015). Entrepreneurship in Regulated Markets: Framing Contests and Collective Action to Introduce Pay TV in the U.S. Academy of Management Journal, 58, 1709-1739.

Hartmann, N. N., Wieland, H., \& Vargo, S. L. (2018). Converging on a New Theoretical Foundation for Selling. Journal of Marketing, $82(2), 1-18$

Hoffman, A. J. (1999). Institutional Evolution and Change: Environmentalism and the U.S. Chemical Industry. The Academy of Management Journal, 42, 351-371. 
Humphreys, A. (2010). Megamarketing: The Creation of Markets as a Social Process. Journal of Marketing, 74, 1-19.

Kim, D. J., \& Kogut, B. (1996). Technological platforms and diversification. Organization Science, 7(3), 283-301.

Kjellberg, H., \& Helgesson, C. F. (2006). Multiple versions of markets: Multiplicity and performativity in market practice. Industrial Marketing Management, 35, 839-855.

Kjeldgaard, D., Askegaard, S., Rasmussen, J. Ø., \& Østergaard, P. (2017). Consumers' collective action in market system dynamics. Marketing Theory, 17(1), 51-70.

Latour, B. (2005). Reassembling the social. An introduction to actornetwork-theory. Oxford University Press.

Martin, D. M., \& Schouten, J. W. (2014). Consumption-Driven Market Emergence. Journal of Consumer Research, 40.

Mele, C., Pels, J., \& Storbacka, K. (2015). A holistic market conceptualization. Journal of the Academy of Marketing Science, 43(1), 100-114.

Möller, K., Nenonen, S., \& Storbacka, K. (2020). Networks, ecosystems, fields, market systems? Making sense of the business environment. Industrial Marketing Management, 90, 380-399.

Moran, G., \& Mountford, N. (2021). Please don't put a price on our lives": Social media and the contestation of value in Ireland's pricing of orphan drugs. In Geiger, S. (Ed) Healthcare Activism: Markets, Morals, and the Collective Good, Oxford University Press, U.K.

Mountford, N. (2019). Managing-by-Proxy, Organizational networks as institutional levers in evolving public good markets. Journal of Business Research, 98, 92-104.

Mountford, N., \& Geiger, S. (2020). Duos and duels in field evolution: How governments and interorganizational networks relate. Organization Studies, 41(4), 499-522.

Nenonen, S., Kjellberg, H., Pels, J., Cheung, L., Lindeman, S., Mele, C., Sajtos, L., \& Storbacka, K. (2014). A new perspective on market dynamics: Market plasticity and the stability-fluidity dialectics. Marketing Theory, 14(3), 269-289.

Nenonen, S., Storbacka, K., \& Windahl, C. (2019). Capabilities for market-shaping: triggering and facilitating increased value creation. Journal of the Academy of Marketing Science, 47(4), 617-639.

Nøjgaard, M. Ø., \& Bajde, D. (2020). Comparison and cross-pollination of two fields of market systems studies. Consumption Markets \& Culture, 1-22.

Oakes, L. S., Townley, B., \& Cooper, D. J. (1998). Business Planning as Pedagogy: Language and Control in a Changing Institutional Field. Administrative Science Quarterly, 43, 257-292..

Owen-Smith, J., \& Powell, W. W. (2008). The SAGE Handbook of Organizational Institutionalism. SAGE Publications Ltd.

Onyas, W. I., \& Ryan, A. (2015). Agencing markets: Actualizing ongoing market innovation. Industrial Marketing Management, $44,13-21$.

Patriotta, G. (2020). Actors and Actorhood in Institutional Theory. Journal of Management Studies, 57(4), 867-872.

Patvardhan, S. D., Gioia, D. A., \& Hamilton, A. L. (2015). Weathering a meta-level identity crisis: Forging a coherent collective identity for an emerging field. Academy of Management Journal, $58,405-435$.

Pressey, A. D., Vanharanta, M., \& Gilchrist, A. J. (2014). Towards a typology of collusive industrial networks: Dark and shadow networks. Industrial Marketing Management, 43(8), 1435-1450.

Rainelli Weiss, H., \& Huault, I. (2016). Business as Usual in Financial Markets? The creation of incommensurables as institutional maintenance work. Organization Studies, 37, 991-1015.

Reay, T., \& Hinings, C. R. (2005). The Recomposition of an Organizational Field: Health Care in Alberta. Organization Studies, 26, 351-384.
Rosa, J. A., Porac, J. F., Runser-Spanjol, J., \& Saxon, M. S. (1999). Sociocognitive Dynamics in a Product Market. Journal of Marketing, 63, 64-77.

Scaraboto, D., \& Fischer, E. (2013). Frustrated Fatshionistas: An Institutional Theory Perspective on Consumer Quests for Greater Choice in Mainstream Markets. Journal of Consumer Research, 39(6), 1234-1257.

Scott, R. W. (1995). Institutions and Organizations. Sage.

Scott, W. R., Deschenes, S., Hopkins, K., Newman, A., \& Mclaughlin, M. (2006). Advocacy Organizations and the Field of Youth Services: Ongoing Efforts to Restructure a Field. Nonprofit and Voluntary Sector Quarterly, 35, 691-714.

Sgourev, S. V. (2013). How Paris gave rise to Cubism (and Picasso): Ambiguity and fragmentation in radical innovation. Organization Science, 24, 1601-1617.

Sherer, P. D., \& Lee, K. (2002). Institutional Change in Large Law Firms: A Resource Dependency and Institutional Perspective. The Academy of Management Journal, 45, 102-119.

Thornton, P. H. (2002). The rise of the corporation in a craft industry: Conflict and conformity in institutional logics. Academy of Management Journal, 45, 81-101.

Thornton, P. H., \& Ocasio, W. (1999). Institutional Logics and the Historical Contingency of Power in Organizations: Executive Succession in the Higher Education Publishing Industry, 1958-1990. American Journal of Sociology, 105(3), 801-843.

Van Wijk, J., Stam, W., Elfring, T., Zietsma, C., \& Den Hond, F. (2013). Activists and incumbents structuring change: The interplay of agency, culture, and networks in field evolution. Academy of Management Journal, 56, 358-386.

Vargo, S. L., \& Lusch, R. F. (2016). Institutions and axioms: an extension and update of service-dominant logic. Journal of the Academy of Marketing Science, 44(1), 5-23.

Vargo, S. L., Koskela-Huotari, K., Baron, S., Edvardsson, B., Reynoso, J., \& Colurcio, M. (2017). A systems perspective on marketsToward a research agenda. Journal of Business Research, 79, 260-268.

Vedres, B., \& Stark, D. (2010). Structural Folds: Generative Disruption in Overlapping Groups. American Journal of Sociology, 115(4), 1150-1190.

Voronov, M., \& Weber, K. (2020). People, actors, and the humanizing of institutional theory. Journal of Management Studies, 57(4), 873-884.

Weber, K., Heinze, K. L., \& Desoucey, M. (2008). Forage for thought: Mobilizing codes in the movement for grass-fed meat and dairy products. Administrative Science Quarterly, 53, 529-567.

Zelizer, V.A., (1994). Pricing the priceless child: The changing social value of children. Princeton University Press.

Zietsma, C., Groenewegen, P., Logue, D. \& Hinings, C. R. (2017). Field or fields? Building the scaffolding for cumulation of research on institutional fields. Academy of Management Annals, 11.

Zietsma, C., \& Lawrence, T. B. (2010). Institutional Work in the Transformation of an Organizational Field: The Interplay of Boundary Work and Practice Work. Administrative Science Quarterly, 55(2), 189-221.

Zilber, T. B. (2011). Institutional multiplicity in practice: A tale of two high-tech conferences in Israel. Organization Science, 22, 1539-1559.

Zuckerman, E. (2014). New media, new civics? Policy \& Internet, 6, 151-168.

Publisher's Note Springer Nature remains neutral with regard to jurisdictional claims in published maps and institutional affiliations. 